\title{
АРХЕОЛОГИЧЕСКИЕ ИССЛЕДОВАНИЯ БОТАЙСКОЙ КУЛЬТУРЫ НА СОВРЕМЕННОМ ЭТАПЕ
}

\author{
(C) 2018 г. В.Ф. Зайберт, А. Оутрам
}

В статье кратко изложены основные результаты и перспективные направления изучения ботайской культуры коллективом Международной комплексной казахстанскобританской археологической экспедиции. Особое внимание в статье уделено освещению большой работы, проведенной западными учеными под руководством Алана Оутрама на поселении Ботай по анализу археозоологических, химико-физических и биологических источников из культурного слоя памятника.

Ключевые слова: археология, Ботай, археозоология, геохимия и геофизика, доместикация лошади, генетика человека и животных

Большим международным коллективом ученых - археологов и представителей естественных наук на предстоящие годы поставлены масштабные задачи дальнейших исследований ботайской культуры (энеолит, Урало-Тобольское междуречье). Прежде всего, это связано с принципиальным обновлением концепции возникновения и развития государства и общества Казахстана, активно развивающегося в мировом экономическом и культурном пространствах.

В последние два десятилетия в стране реализовалась беспрецедентная по масштабам и финансовым вложениям государственная программа по изучению и сохранению историко-культурного наследия Казахстана. Сотни и тысячи объектов и артефактов пополнили фонды музеев, архивов и библиотек. Данные источники являются значительным потенциалом для написания новой истории Казахстана. Если использование литературных и архивных письменных источников (на различных языках народов Евразии) не создает особых сложностей отечественным исследователям, то введение в научный оборот данных археологии в свете исторического контекста требует специальной методологии реконструирования и моделирования хозяйственно-культурных типов и духовно-мировоззренческих аспектов. С большим воодушевлением научная и культурная общественность страны приняла и активно работает над современной государственной программой «Рухани жаңғыру». Конечной целью синтеза археологических и историко-культурных источников является доведение последних до уровня этнографических и полу- 
чение представлений о путях трансформации археологической культуры в этнографическую.

История - это жизнь людей в обществе, отдельных личностей во всем многообразии их причинноследственных связей, в определенной окружающей среде в прошлом и настоящем. Исторический процесс образует пласт истории как остаточную систему причинно-следственных связей, заключенную в материальных, письменных и духовных источниках. Чтобы изучать историю, необходимо применять методологию, позволяющую раскрутить в ретроспективном порядке результаты исторического процесса, идущего от настоящего к будущему и восстановить «настоящее» или, как говорят археологи, «древнюю поверхность» определенного хронологического пласта [Зайберт, 2009].

Мировая историческая наука выработала многообразные методы и принципы анализа. Задача исследователя - применить их в своей практике для получения объективных результатов. Изучение ботайской культуры на современном этапе с привлечением ученых ведущих мировых центров и исследовательских учреждений в последние 20 лет дало существенный эффект в деле познания процессов, связанных с одомашниванием лошади, формированием многоотраслевой степной экономики и основных закономерностей взаимодействия социумов и окружающей среды. Взаимодействие с зарубежными специалистами было организовано на основе взаимного научного интереса руководителя ис- следований Ботая В.Ф. Зайберта и профессора Эксетерского университета (Великобритания) археозоолога Алана Оутрама. Между ними установилось и определенное разделение труда - первый разрабатывает вопросы историко-культурных закономерностей, второй проводит инструментальные естественнонаучные исследования на основе самых последних мировых достижений науки и техники в различных областях знаний. Это уникальное взаимодействие позволяет в разы усилить историческую верификацию культурных образований и их природно-экологический и сакральный контексты.

Вот как характеризуются Аланом Оутрамом многолетние казахстано-британские исследования ботайской культуры: «Ботай уже длительное время считается ключевым объектом в понимании доместикации лошади и происхождения пастбищных обществ в Центральной Азии. Под динамичным руководством профессора Виктора Зайберта исследования на Ботае также включали сотрудничество со многими международными учеными, в том числе из Германии, США, Великобритании, России, Франции, Дании, Китая и Литвы. Многие из вовлеченных специалистов являются лидерами в своих областях и применяют передовые методологии для своей работы в Казахстане. В некоторых случаях Ботай был предметом самого первого применения совершенно новых подходов и методов в мире. Памятник вдохновил на значительный уровень исследований и этому способствовал открытый подход Виктора Зайберта к 
Зайберт B.Ф., Оутрам А. Археологические исследования ботайской культуры...

сотрудничеству. Обширное наследие исследований на Ботае заключается не только в его несомненном археологическом значении, но и в связях между разными учеными и в новых подходах, которые этому способствовали. Ботай также был центром обучения молодого поколения археологов. Виктор Зайберт подготовил много сотен казахстанских студентов, также в работу на Ботае были вовлечены зарубежные студенты, магистранты и докторанты» [Outram, 2017].

Исследования на поселении Ботай стартовали в 1980 г., а с 1991 года, с провозглашением независимости, международные исследования на Ботае значительно расширились [Зайберт, 2009]. Основные направления исследований изложены в рамках перекрестных тем и методологий: 30оархеологии; микроморфологии почв, геохимии и геофизики; археоботаники; определения диеты из изотопов и остатков; определения ДНК.

Исследования в области зооархеологии. В 1990-х годах ряд исследователей зооархеологов Дэвид Энтони и Доркас Браун (колледж Хартвик, США); Норберт Бенеке и Анжела фон ден Дриш (Германия), Марша Левин (Кембридж, Великобритания) и Сандра Олсен (Музей естественной истории Карнеги, США) опубликовали обзорные статьи на тему изучения зооархеологической коллекции Ботая в широком контексте дебатов о приручении лошадей.

Кроме традиционных хорошо известных естественнонаучных методов мы, пытаясь установить доказательства практики верховой езды в Ботае, разработали новые палеопато- логические методы. Участники экспедиции Д. Энтони и Д. Браун выработали новый метод, предназначенный для определения износа, который может вызвать скос на первом премоляре, для доказательства использования лошади для верховой езды. Рассматривались также возможные патологии, которые могли развиться в позвоночном столбе лошади в результате воздействия всадника. Д. Энтони и Д. Браун поддерживали теорию одомашнивания лошади в период до ботайской культуры с полным всадническим использованием животных [Anthony, Brown, 2011].

Следующее десятилетие стало началом новых зооархеологических исследований командой Алана Оутрама - Робина Бендри (Винчестер, Великобритания) и Алексея Каспарова (РАН, Россия). Р. Бэндри разработал два новых критерия для определения степени износа, включая модели износа на передней части премоляров, а также костную патологию диастемы [Bendrey, 2007]. Команда исследователей смогла применить это к остеологическим коллекциям на Ботае и обнаружила доказательства обоих типов патологии [Outram et al., 2009]. Таким образом, ботайские лошади, вероятно, использовались для верховой езды. Хотя точная хронология и характер коневодства в ботайской культуре, безусловно, все еще могут обсуждаться, эти направления исследований значительно увеличили ценность зооархеологических доказательств того, что ботайские лошади были одомашнены [Outram et al., 2014; 2015]. 
В настоящее время международные зооархеологические исследования включают в себя геометрический морфометрический (GMM) анализ эмалевых складок в конских зубах как индикатор происхождения или породы (Хелана Райан (Эксетер, Великобритания), Леонид Чинделевич (Симон Фрейзер, Канада), работающие с Аланом Оутрамом)). Было продемонстрировано, что этот метод эффективен и выявляет различия между некоторыми современными породами лошадей [Seetah et al., 2014].

Микроморфология почв, геохимия и геофизика. На Ботае мы видим, что все лошади были, скорее всего, умерщвлены в процессе массового забоя.

Наличие большого количества в древнем навозе следов в виде микроскопической структуры почвы и ее химического состава позволили найти множество доказательств того, что лошадиный навоз присутствовал в культурном слое и составлял базовые структуры жилищ [French, Kousoulakou, 2003]. Работая с командой Оутрама, Айви Оуэнс (Кембридж и Эксетер, Великобритания) продолжила исследования микроморфологии почв в Ботае.

Как геофизические, так и геохимические исследования могут быть исключительно полезны при определении корральных особенностей. Команда Олсен, работавшая на поселении ботайской культуры Красный Яр в 2000 г., определила потенциальный загон, обнаруженный в магнитометрической съемке в виде трапециевидной оболочки [Olsen et al., 2006], которая имела также повышенный уровень фосфора. В 2008 г. команда провела магнитную съемку c помощью флуоггейтной градиометрии на поселении Ботай. Этот крупномасштабный анализ сопровождался некоторыми геохимическими разрезами и регистрацией моделей эрозии почвы. Позднее раскопки, проведенные командой Зайберта и Оутрама, подтвердили наличие жилого комплекса с загоном. Четкое присутствие элементов загона является убедительным свидетельством животноводства.

Археоботаника. Прямые доказательства эксплуатации одомашненных культур в северных степях Казахстана в доисторический период исключительно ограничены [Outram, 2015]. До недавнего времени было проведено очень мало систематического просеивания почвенных отложений осадков для извлечения обугленных археоботанических остатков. В 2011 г. Ботай стал объектом одной из первых таких программ в регионе, когда известный археоботаник Мартин Джонс (Кембридж, Великобритания) привлек значительную группу исследователей для совместной работы с командами В. Зайберта и А. Оутрама на раскопках поселения Ботай. Ключевыми сотрудниками из Кембриджа были Гидре МотузайтеМатузевичюте Кин, Эмма Лайтфут и Синьи Лю. Мартин Джонс особенно интересовался поиском доказательств использования проса [Jones et al., 2011]. Этот транс-евразийский обмен должен был включать торговые пути через степь, но необходимо было установить, что это за маршрут. 
Зайберт B.Ф., Оутрам A. Археологические исследования ботайской культуры...

Работа по-прежнему продолжается, но обширный отбор проб не дает никаких доказательств существования отечественных сельскохозяйственных культур, некоторые ограниченные данные имеются об использовании дикорастущих растений [Jones et al., 2016]. Команда М. Джонса также взяла образцы почвы для изучения фитолитов, присутствующих на этом участке. Образцы почвы могут быть протестированы на наличие биомаркера миллиацина, который указывает на присутствие проса [Arnaud et al., 2016]. В 2017 г. Э. Ананьевская (Вильнюс, Литва, ранее Эксетер), работавшая с Гидре МотузайтеМатузевичюте Кин (Вильнюс, ранее Кембридж), взяла образцы для тестирования на миллиацин.

Определение диеть из изотопов и остатков органики. Предметом исследований являлась также реконструкция рациона жителей Ботая. Костные материалы были проверены на соотношение содержания изотопов углерода и азота. Эти исследования провели Томсен О'Коннелл (Кембридж, Великобритания) и Роберт Хеджес (Оксфорд, Великобритания). Высокие уровни трофиков были показаны во многих образцах из доисторической степи, включая Ботай, что свидетельствует о высокой зависимости жителей от продуктов животного происхождения с дальнейшим ее усилением от пресноводного рыболовства [O'Connell et al., 2003].

Стенки неглазурованных керамических сосудов поглощают жировые остатки, которые могут сохраняться исключительно хорошо в течение тысячелетий. Полудегради- рованные, абсорбированные липидные остатки животных жиров трудно химически отделить друг от друга, но некоторые различия могут быть сделаны путем проведения расширенного анализа с помощью специфического разделения соединений и установления стабильных изотопных отношений углерода. Этим процессом можно выделять жиры свиней, лошадей и жвачных животных, а также мясо и молочные жиры жвачных. Предположение, что ботайцы ели мясо лошади было логичным, а доказательство потребления молока кобылы имеет большое значение для решения споров о приручении лошадей. Проблема заключалась в том, что с помощью только соотношения изотопов углерода не различить мясо лошади и молочные жиры. В итоге был разработан совершенно новый метод, в котором использованы углерод и водородные стабильные изотопные отношения. Этот новый метод хорошо показал себя на современных образцах и также оказался успешным в определении конского молока на фрагментах керамики Ботая [Stear, 2008]. Доение является явным свидетельством того, что лошади Ботая были объезжены [Outram, 2014]. Ботай был также первым археологическим подтверждением водородноустойчивых соотношений изотопов в липидных остатках.

В 2017 г. А. Оутрам взял образцы зубного исчисления из костей скелета человека, найденного на Ботае, для отправки д-ру Николь Бойвин и Шеван Вилкин (Макс Планк, Йена, Германия) для протеомического анализа. Присутствие белка в потребля- 
емой людьми пище проявляется тем, что он накапливается и сохраняется в останках зубов и может быть идентифицирован с помощью новых методов масс-спектрометрии.

Древняя ДНК. В последние годы генетические исследования были усовершенствованы за счет разработки методов высокопроизводительного упорядочения следующего поколения. С 2015 г. Людовик Орландо (Geogenetics, Копенгаген, а теперь CNRS, Тулуза) работает с В Зайбертом и А. Оутрамом для сбора генетических образцов лошадей из Ботая и других объектов для сравнения в границах центрально-азиатской степи. Однако в 2017 г. обнаружение редких новых останков человека означало возможность объединения этих исследований с геномикой человека. Известный специалист Эске Уиллерслев (Копенгаген и Кембридж) присоединился к работе по отбору проб. Открытие новых человеческих останков также привело Аврама к тому, чтобы привлечь своего коллегу по остеоархеологии Катриона Маккензи. Геномная работа осуществилась быстро и результаты были опубликованы. Таким образом, в Ботае проведена значительная работа для определения геномики древнего человека, местной фауны.

Bblводы. Таким образом, поселение Ботай - невероятно важный объект, который является центром ключевой дискуссии ученых всего мира. Емкое, цельное, совокупное, многовекторное понятие «история» в обиходе общества расчленяется в процессе познания самой истории или исторического контекста на ряд предметов исследования: «культурогенез» - как глобальный процесс адаптации общества в окружающей среде, выработка систем жизнеобеспечения [Массон, 1981]; «антропогенез» [Захарук, 1976, с. 6-10]; «этногенез» [Токарев, 1964, с. 48-59]; «палеогенезис» [Gaunitz, 2018]; «политогенез» и др. [Чубарьян, 1989]. Каждый предмет исследования основан на формировании у ученых не только общепрофессиональных знаний, но и специальных, специфических навыков, принципов и методик анализа источников.

Культура древних племен и народов Казахстана складывалась и развивалась на фоне грандиозных изменений природного и социального характера, происходивших в каменном веке (палеолит-мезолит-неолит) на обширной территории. В целом, древнюю историю можно образно представить как гигантскую Человеческую лабораторию, где на протяжении многих тысячелетий через практику, мысль, ошибки, достижения, анализ, синтез, взлеты, падения, совершенствования и деградации происходит моделирование Человека, человеческого «Я» как отражение социального состояния. «Мы» часть Природы, вышедшая из нее, но не порвавшая с ней. Именно поэтому «потребности человека социально обусловлены и культура «отвечает» на них как система социальных связей, причем отвечает не однозначно, а в разных исторических условиях по-разному» [Хотинский, 1977].

Наконец, важную роль в формировании культуры играет окружающая среда, которая в процессе 
Зайберт B.Ф., Оутрам A. Археологические исследования ботайской культуры...

жизнедеятельности людей преобразуется в культурный и сакральный ландшафт, означающий установление биосоциальных, сакральных и профанных отношений.

Комплексные исследования археологических памятников в ряде регионов Казахстана показали, что развитие древних социумов происходило, с одной стороны, в сложной взаимосвязи с окружающей средой, с другой, - в многочисленных переплетениях сфер материальной и духовной жизни внутри общественного организма.

Современные методы исследования позволяют с достаточно высокой точностью выявить сезонность хозяйственной или производственной деятельности человека, а также время забоя скота, период захоронения умерших и т. д. Отсюда вытекает возможность создания модели хо- зяйственной и социально-духовной жизни древнего социума в рамках календарного годичного цикла. Лишь понимание древними людьми значения формирования производственного цикла по временам года обеспечивало стабильность социума, его воспроизводство и развитие как устойчивой системы в пространстве и во времени. Этап формирования календарного цикла в древних культурах и можно, пожалуй, связывать с началом пути к цивилизации. Складывание календарного цикла проходило в среде первых земледельцев и скотоводов. Это мы видим на примере долинных цивилизаций Востока, раннеклассовых обществ Средиземноморья, а также в реконструированных хозяйственно-культурных типах степной Евразии.

\section{ЛИТЕРАТУРА}

1. Зайберт В.Ф. Ботайская культура. Алматы: «КазАкпарат», 2009. 576 с.

2. Захарук Ю.Н. Историзм: проблемы археологии и этнографии // Историзм археологии: методические проблемы: тез. докл. конф. М., 1976. С. 6-10.

3. Левин М. Истоки конного хозяйства на евразийской степи // Поздняя доисторическая эксплуатация евразийской степи. Левин М., Рассамакин Ю., Кисленко А., Татаринцева Н. (ред.). Кембридж: Институт Макдональда, 1999. С. 5-58.

4. Левин М. Изучение критериев раннего приручения лошадей // Следы предков: исследования в честь Колина Ренфрю. Джонс М. (изд.). Кембридж: Институт Макдональда, 2004. С. 115-26.

5. Массон В.М. Основные направления культурно-исторического процесса // Становление производства в эпоху энеолита и бронзы: по материалам Южного Туркменистана. М.: «Наука», 1981. С. 35-48.

6. Токарев С.А. Проблемы типов этнических общностей (к методологическим проблемам этнографии) // Вопросы философии. 1964. № 11. С. 48-59.

7. Хотинский Н.А. Голоцен Северной Евразии: опыт трансконтинентальной корреляции этапов развития растительности и климата (К X Конгрессу YNAUA (Beликобритания, 1977); 8). М.: «Наука», 1977. С. 13-16.

8. Чубарьян А.О. Опыт мировой истории и идеологии обновления // Всеобщая история: дискуссии, новые подходы. М., 1989. Вып. 1. С. 7-17. 
9. Arnaud F., Poulenard J., Giguet-Covex C., Wilhelm B., Révillon S., Jenny J.P., Revel M., Enters D., Bajard M., Fouinat L., Doyen E. Erosion under climate and human pressures: An alpine lake sediment perspective // Quaternary Science Reviews. 2016. 152. P. 1-18.

10. Bendrey $R$. New methods for the identification of evidence for bitting on horse remains from archaeological sites // JAS. 2007. 34 (7). P. 1036-1050.

11. French C., Kousoulakou M. Geomorphological and micromorphological investigations of palaeosols, valley sediments and a sunken floored dwelling at Botai, Kazakhstan // Levine M.A., Renfrew C., Boyle K.V. (eds). Prehistoric Steppe Adaptation and the Horse. Cambridge: McDonald Institute, 2003. P. 105-114.

12. Jones M.A., Hunt H.A., Kneale C.A., Lightfoot E.M., Lister D.I., Liu X.I., Motuzaite-Matuzeviciute G.I. Food globalisation in prehistory: The agrarian foundations of an interconnected continent // Journal of the British Academy. 2016. 4. P. 73-87.

13. O'Connell T., Levine M., Hedges R. The importance of fish in the diet of Central Eurasian peoples from the Mesolithic to the Early Iron Age // Levine M., Renfrew C., Boyle K. (eds) Prehistoric Steppe Adaptation and the Horse. Cambridge: McDonald Institute for Archaeological Research, 2003. P. 253-268.

14. Olsen S.A., Bradley B., Maki D., Outram A. Community organization among Copper Age sedentary horse pastoralists of Kazakhstan // Peterson D.L., Popova L.M., Smith A.T. (eds) Beyond the steppe and the sown: Proceedings of the 2002 University of Chicago Conference on Eurasian Archaeology. Leiden: Brill, 2006. P. 89-111.

15. Outram A.K., Stear N. A., Bendrey R., Olsen S., Kasparov A., Zaibert V., Thorpe N., Evershed R.P. The earliest horse harnessing and milking// Science. 2009. 323 (5919). P. 1332-1335.

16. Outram A.K. Animal Domestications // Oxford Handbook of the Archaeology and Anthropology of Hunter-Gatherers. Cumming V., Jordan P., Zvelebil M. (eds). Oxford: Oxford University Press, 2014. P. 749-763.

17. Outram A.K. Pastoralism // The Cambridge World History, Vol. II: A World with Agriculture, 12,000 BCE - 500 CE. Barker G., Goucher C. (eds). Cambridge: Cambridge University Press, 2015. P. 161-185.

18. Seetah K., Cucchi T., Dobney K., Barker G. A geometric morphometric re-evaluation of the use of dental form to explore population differences in horses (Equus caballus) and its potential zooarchaeological application // JAS. 2014. 41. P. 904-910.

19. Stear N.A. Changing patterns of animal exploitation in the prehistoric Eurasian steppe: an integrated molecular, stable isotope and archaeological approach. Unpublished PhD Thesis. University of Bristol, 2008.

\section{Сведения об авторах:}

Зайберт Виктор Федорович - доктор исторических наук, профессор, директор НИИ «Археология и степные цивилизации», Казахский национальный университет им. аль-Фараби (г. Алматы, Казахстан); zaibert_ku@mail.ru

Оутрам Алан - доктор археологии, профессор, Эксетерский университет (г. Эксетер, Великобритания)

\section{ҚАЗІРГІ КЕЗЕНДЕГІ БОТАЙДА ЖУРГІЗІЛГЕН АРХЕОЛОГИЯЛЫҚ ЗЕРТТЕУЛЕР}

\section{В.Ф. Зайберт, А. Оутрам}

Мақалада халықаралық кешенді Қазақстан-Британ археологиялық экспедициясының ұжымымен Ботай мәдениетінің зерттелуіндегі басты нәтижелер мен басты бағыттары айтылады. Онда негізінен Алан Оутрамның жетекшілігімен батыс ғалымдарының Ботай қонысының мәдени қабаттарынан археозоологиялық, 
Зайберт B.Ф., Оутрам А. Археологические исследования ботайской культуры...

химиялық, физикалық, биологиялық сараптамалар жүргізген үлкен еңбектеріне баса назар аударылған.

Түйін сөздер: археология, Ботай, археозоология, геохимия, геофизика, жылқының доместикациясы, адам және жануарлардың генетикасы

\title{
ARCHAEOLOGICAL RESEARCH OF BOTAY CULTURE AT THE PRESENT STAGE
}

\author{
V.F. Zaibert, A. Outram
}

This article encapsulates the main results and promising directions in the study of Botay culture by the team of international integrated Kazakh-Britain archaeological expedition. Particular attention in the article is paid to the large amount of work done by Western scientists under the leadership of Alan Outram at the Botay settlement on the analysis of archaeozoological and chemical-physical, biological sources from the cultural layer of the monument.

Keywords: archaeology, Botay, archaeozoology, geochemistry and geophysics, horse domestication, human and animal genetics

\section{REFERENCES}

1. Zaibert, V. F. 2009. Botaiskaya kultura (Botay culture). Almaty: “KazAkparat” Publ. (in Russian).

2. Zaharuk, Yu. N. 1976. In Istorizm arheologii: metodicheskie problem: tez. konf. (Historicism of archaeology: methodical problems: proc. conf.). Moscow, 6-10 (in Russian).

3. Levin, M. 1999. In Levin, M., Rassamakin, Yu., Kislenko, A., Tatarinceva, N. (eds.). Pozdnyaya doistoricheskaya ekspluataciya evraziiskoi stepi (The late prehistoric exploitation of the Eurasian steppe). Cambridge: Makdonald Institut, 5-58 (in Russian).

4. Levin, M. 2004. In Jones, M. (ed.) Sledy predkov: issledovaniya v chest Kolina Renfru (Ancestral Trails: Studies in Honor of Colin Renfrew). Cambridge: Makdonald Institut, 115-126 (in Russian).

5. Masson, V. M. 1981. In Stanovlenie proizvodstva v epohu eneolita i bronzy (The formation of production in the era of the Eneolithic and Bronze). Moscow, 35-48 (in Russian).

6. Tokarev, S. A. 1964. In Voprosy filosofii, 11, 48-59 (in Russian).

7. Hotinskii, N. A. 1977. Golocen Severnoi Evrazii (The Holocene of Northern Eurasia). Moscow: "Nauka" Publ. (in Russian).

8. Chubaryan, A. O. 1989. In Vseobshchaya istoriya: diskussii, novye podhody (Universal history: discussions, new approaches), 1. Moscow, 7-17 (in Russian).

9. Arnaud, F., Poulenard, J., Giguet-Covex, C., Wilhelm, B., Révillon, S., Jenny, J. P., Revel, M., Enters, D., Bajard, M., Fouinat, L., Doyen, E. 2016. In Quaternary Science Reviews, 152, 1-18.

10. Bendrey, R. 2007. In JAS, 34 (7), 1036-1050.

11. French, C., Kousoulakou, M. 2003. In Levine, M. A., Renfrew, C., Boyle, K. V. (eds.). Prehistoric Steppe Adaptation and the Horse. Cambridge: McDonald Institute, P. 105-114.

12. Jones, M. A., Hunt, H. A., Kneale, C. A., Lightfoot, E. M., Lister, D. I., Liu, X. I., Motuzaite-Matuzeviciute, G. I. 2016. In Journal of the British Academy, 4, 73-87.

13. O’Connell, T., Levine, M., Hedges, R. 2003. In Levine, M., Renfrew, C., Boyle, K. (eds.) Prehistoric Steppe Adaptation and the Horse. Cambridge: McDonald Institute for Archaeological Research, 253-268.

14. Olsen, S. A., Bradley, B., Maki, D., Outram, A. 2006. In Peterson, D. L., Popova, L. M., Smith, A. T. (eds.) Beyond the steppe and the sown: Proceedings of the 2002 University of Chicago Conference on Eurasian Archaeology. Leiden: Brill, 89-111.

15. Outram, A. K., Stear, N. A., Bendrey, R., Olsen, S., Kasparov, A., Zaibert, V., Thorpe, N., Evershed, R. P. 2009. In Science. 323 (5919), 1332-1335. 
16. Outram, A. K. 2014. In Cumming V., Jordan P., Zvelebil M. (eds.). Oxford Handbook of the Archaeology and Anthropology of Hunter-Gatherers. Oxford: Oxford University Press, 749-763.

17. Outram, A. K. 2015. In Barker, G., Goucher, C. (eds). The Cambridge World History, Vol. II: A World with Agriculture, 12,000 BCE - 500 CE. Cambridge: Cambridge University Press, 161-185.

18. Seetah, K., Cucchi, T., Dobney, K., Barker, G. 2014. In JAS, 41, 904-910.

19. Stear, N. A. Changing patterns of animal exploitation in the prehistoric Eurasian steppe: an integrated molecular, stable isotope and archaeological approach. Unpublished $\mathrm{PhD}$ Thesis. University of Bristol, 2008.

\section{About the Authors:}

Zaibert Viktor F. Doctor of Historical Sciences, Professor, Director of the Research Institute "Archaeology and Steppe Civilizations", Al-Farabi Kazakh National University, Almaty, Kazakhstan; zaibert_ku@mail.ru

Outram Alan. Doctor of Archaeology, Professor, University of Exeter (Exeter, UK)

Мүдделер қақтығысы туралы ақпаратты ашу. Авторлар мүдделер қақтығысының жоқтығын мәлімдейді. / Раскрытие информации о конфликте интересов. Авторы заявляют об отсутствии конфликта интересов. / Disclosure of conflict of interest information. The authors claims no conflict of interest.

Мақала туралы ақпарат / Информация о статье / Information about the article.

Редакцияға түсті / Поступила в редакцию / Entered the editorial office: 23.10.2018.

Рецензенттер мақұлдаған / Одобрено рецензентами / Approved by reviewers: 30.10.2018

Жариялауға қабылданды / Принята к публикации / Accepted for publication: 06.11.2018. 